Braz J Med Biol Res, November 2011, Volume 44(11) 1184-1193

doi: 10.1590/S0100-879X2011007500132

Outcomes and organ dysfunctions of critically ill patients with systemic lupus erythematosus and other systemic rheumatic diseases

O.T. Ranzani, L.C. Battaini, C.E. Moraes, L.F.L. Prada, J.V. Pinaffi, F.P. Giannini, S.K. Shinjo, L.C.P. Azevedo and M. Park

The Brazilian Journal of Medical and Biological Research is partially financed by

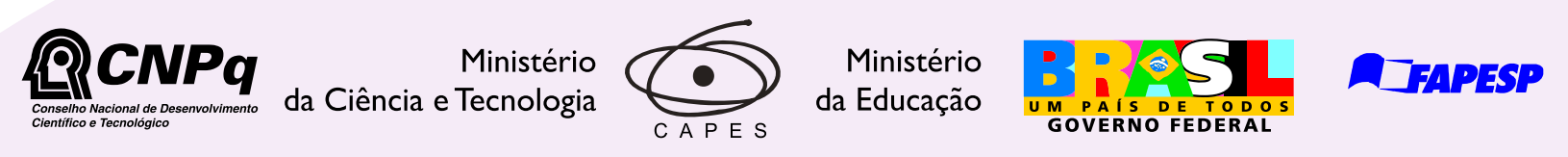

Institutional Sponsors
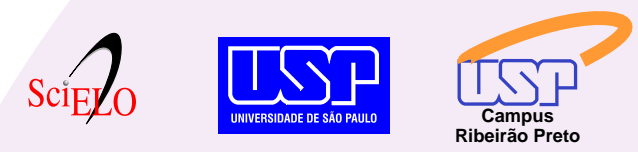

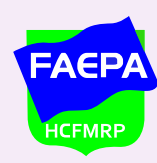

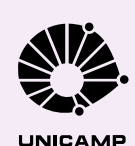

UNICAMP
Ф SHIMADZU

Explore High - Performance MS Orbitrap Technology In Proteomics \& Metabolomics

analitica Thermo 


\title{
Outcomes and organ dysfunctions of critically ill patients with systemic lupus erythematosus and other systemic rheumatic diseases
}

\author{
O.T. Ranzani ${ }^{1}$, L.C. Battaini ${ }^{1}$, C.E. Moraes ${ }^{1}$, L.F.L. Prada ${ }^{1}$, J.V. Pinaffi ${ }^{1}$, \\ F.P. Giannini ${ }^{1}$, S.K. Shinjo ${ }^{2}$, L.C.P. Azevedo ${ }^{1}$ and M. Park ${ }^{1}$ \\ ${ }^{1}$ Unidade de Terapia Intensiva, Departamento de Emergência, Hospital das Clínicas, Faculdade de Medicina, \\ Universidade de São Paulo, São Paulo, SP, Brasil \\ ${ }^{2}$ Divisão de Reumatologia, Hospital das Clínicas, Faculdade de Medicina, \\ Universidade de São Paulo, São Paulo, SP, Brasil
}

\begin{abstract}
Our objective was to compare the pattern of organ dysfunctions and outcomes of critically ill patients with systemic lupus erythematosus (SLE) with patients with other systemic rheumatic diseases (SRD). We studied 116 critically ill SRD patients, 59 SLE and 57 other-SRD patients. The SLE group was younger and included more women. Respiratory failure (61\%) and shock (39\%) were the most common causes of ICU admission for other-SRD and SLE groups, respectively. ICU length-of-stay was similar for the two groups. The 60-day survival adjusted for the groups' baseline imbalances was not different $(P=0.792)$. Total SOFA scores were equal for the two groups at admission and during ICU stay, although respiratory function was worse in the other-SRD group at admission and renal and hematological functions were worse in the SLE group at admission. The incidence of severe respiratory dysfunction (respiratory SOFA $>2$ ) at admission was higher in the other-SRD group, whereas severe hematological dysfunction (hematological SOFA >2) during ICU stay was higher in the SLE group. SLE patients were younger and displayed a decreased incidence of respiratory failure compared to patients with other-SRDs. However, the incidences of renal and hematological failure and the presence of shock at admission were higher in the SLE group. The 60-day survival rates were similar.
\end{abstract}

Key words: Critical illness; Rheumatic diseases; Systemic lupus erythematosus; Intensive care units; Multiple organ failure; Patient outcome assessment

\section{Introduction}

Systemic rheumatic diseases (SRDs) are common in the general population $(1,2)$. In addition, they are one of the leading causes of death among young and middle-aged women (1). Approximately 10 to $25 \%$ of all patients with SRDs visiting Emergency Departments require hospital admission, and $30 \%$ of these patients are admitted to the intensive care unit (ICU) (3). The mortality of critically ill rheumatologic patients is higher than for the general ICU population with similar disease severity $(2,4-6)$.

Multiple organ dysfunction syndrome (MODS) is the most common cause of death in the ICU population (7). The severity of MODS measured by the sequential organ failure assessment (SOFA) score, as well as SOFA-derived variables, are strongly associated with clinical outcomes $(8,9)$. Currently, there are few data regarding MODS evaluation in critically ill rheumatologic patients (2). Moreover, the accuracy of other physiologically based severity scores, such as the acute physiology and chronic health evaluation II (APACHE II), in predicting clinical outcomes in these patients is unclear $(5,10,11)$.

Patients with systemic lupus erythematosus (SLE) usually present polymorphic manifestations. In view of this complexity, we hypothesized that SLE patients might have worse outcomes than other-SRD patients. Therefore, the primary aim of this study was to determine whether critically ill patients with SLE have the same incidence and severity of organ dysfunction as critically ill patients with other-SRDs and to compare their clinical outcomes. Secondarily, we attempted to determine the prognostic factors in a general sample of SRD patients and to report the incidence of organ dysfunctions and outcomes in this population.

Correspondence: O.T. Ranzani, HC, FM-USP, Rua Eneas C. de Aguiar, 255, Sala 6040, 6o andar, 05403-000 São Paulo, SP, Brasil. E-mail: otavioranzani@uol.com.br

Received March 1, 2011. Accepted September 23, 2011. Available online October 14, 2011. Published November $14,2011$. 


\section{Patients and Methods}

\section{Study design and sampling}

This was a single-center cohort study consisting of 1780 consecutive critical patients admitted to the clinical ICU of the Emergency Department, Hospital das Clínicas, Faculdade de Medicina, Universidade de São Paulo (HCFMUSP), in Brazil. Data were retrieved from April 2003 to January 2010, and all variables were collected prospectively; however, hypotheses were generated before data analysis and after data collection. The present study was approved by the Ethics Committee (CAPPesq) of Hospital das Clínicas, Universidade de São Paulo. Due to its strictly observational design, informed consent was waived.

All patients with the diagnoses of SRD were eligible for inclusion, and only the first ICU admission was considered. Only patients with SRDs diagnosed either before or during the ICU stay were retrieved. The SRDs analyzed in the present study were as follows: SLE (12), polymyositis/dermatomyositis (13), Wegener's granulomatosis (14), rheumatoid arthritis (15), mixed connective tissue disease (16), spondyloarthritis (17), systemic sclerosis (18), Sjögren syndrome (19), primary antiphospholipid syndrome (20), pulmonary-renal syndrome (21), Takayasu's arteritis (22), Behçet's disease (23), ChurgStrauss syndrome (24), and adult-onset Still's disease (25). The exclusion criteria were as follows: SRDs induced by drugs and paraneoplastic syndromes, and rheumatic diseases that were irrelevant to our purpose, such as fibromyalgia, osteoarthritis, rheumatic fever, gout, and undefined SRD.

We included 116 critically ill patients with SRD from the 1780 admitted patients (7\%). Patients were clustered into SLE (59 patients) and other-SRD (57 patients) groups.

\section{Data collection}

Data were extracted from our database, including demographics (age, gender, ethnicity), co-morbidities (systemic arterial hypertension, diabetes mellitus, chronic renal failure, chronic obstructive pulmonary disease, chronic liver disease, chronic heart failure, infection, previous thrombotic event), admission diagnosis, source of admission, type of admission, use of noninvasive positive pressure ventilation (NPPV), mechanical ventilation (MV), renal replacement therapy (RRT), or vasoactive drugs. The follow-up of patients was extended to death or hospital discharge, and the ICU and hospital length of stay (LOS) were recorded.

\section{Definitions}

Infections. Defined by microbiologically documented processes (bacteriological and opportunistic) or suspicious (e.g., suggested by radiographic, clinical and/or laboratory findings). Sepsis syndrome, severe sepsis and septic shock were defined according to the Consensus Conference (26).

Activity of rheumatic disease (flare). Acute exacerbation attributable to SRD, after the exclusion of infections, drug reactions, metabolic disturbances, and hypervolemia based on laboratory and clinical data.

Infection and flare. Defined when it was not possible to characterize only one of the previous conditions.

Adverse reaction from treatment drugs. Life-threatening severe reactions to drugs used in the treatment of the respective SRD.

Thrombotic event. Defined as deep vein thrombosis, arterial thrombosis and/or pulmonary embolism. Each of these diagnoses required radiographic or pathological documentation.

Bleeding. Gastrointestinal tract or central nervous system bleeding (e.g., intracranial hemorrhage or acute subarachnoid hemorrhage) as well as alveolar hemorrhage, which was diagnosed according to established criteria (27).

Shock. In this category, we included all patients with cardiovascular dysfunction (systolic blood pressure $<90 \mathrm{mmHg}$ refractory to $20-30 \mathrm{~mL} / \mathrm{kg}$ of crystalloid volume infusion or need for vasopressor therapy).

Acute renal failure. Defined as a creatinine increase $>0.3$ $\mathrm{mg} / \mathrm{dL}$ between two measurements up to $48 \mathrm{~h}$ apart, acute RRT requirement at any time (excluding chronic dialysis) or urinary flow $<0.5 \mathrm{~mL} \cdot \mathrm{kg}^{-1} \cdot \mathrm{h}^{-1}$ for 6 consecutive hours. Patients with chronic renal failure were considered in this definition (acute renal failure exacerbating chronic dysfunction) if creatinine was increased 1.5-fold from baseline (28).

Respiratory failure. Patients with an oxygen saturation $<90 \%$ or $\mathrm{PaO}_{2}<60 \mathrm{mmHg}$ at room air, patients with a P/F ratio $<300$ or need for mechanical ventilation due to respiratory causes (excluding neurological events and anesthesia for surgery).

Central nervous system disturbances. Patients with stroke, intracranial hemorrhage, meningitis, seizures, or coma.

\section{Organ function and severity scores}

Clinical and laboratory data for the APACHE II were reported as the worst value within $24 \mathrm{~h}$ after admission (29). A daily evaluation of any degree of organ dysfunction according to the SOFA score was performed (30), with the worst value for each of the six organ systems (neurological, cardiovascular, respiratory, renal, hepatic, and hematological) being collected on admission and every $24 \mathrm{~h}$ thereafter. Severe dysfunction was defined as a SOFA score higher than 2 for the organ in question (30). SOFA-derived variables were calculated as follows: total SOFA was calculated as the sum of each organ score daily during the ICU stay for each patient; maximum SOFA was the highest score of total SOFA during the ICU stay; mean SOFA was calculated as the arithmetic mean of total SOFAvalues during the ICU stay; total maximum SOFA(TMS) was calculated as the sum of the worst score for each organ independent of the day, and delta SOFA was the difference between the maximum SOFA and total SOFA at admission. We also recorded the day of the ICU stay during which the maximum SOFA occurred $(9,30)$.

\section{Statistical analysis}

The normality of variables was tested using the Kolmogorov- 
Smirnov goodness-of-fit model. Data are reported as means \pm SD or median and 25 th and 75 th percentiles if they were parametrically ornon-parametrically distributed, respectively. Baseline characteristics of the SLEand other-SRD groups were compared using the Mann-Whitney testor the unpaired $t$-testas appropriate. The Fisher exacttestor chi-square statistics (with Yates correction) were used for dichotomous variables. The Kaplan-Meier curve was used to evaluate the survival of both groups; the probability of survival was compared using the log-rank test. To compare the effect of imbalances (age, gender, chronic renal failure, chronic lung disease, admission syndrome, and hemorrhage evidence) between SLE and other-SRD patients, the Cox proportional hazard analysis was used.

To evaluate the prognostic factors for in-hospital mortality among all 116 patients, we performed a binary logistic regression. After univariate analysis, variables with $P$ values less than 0.2 were included in multivariate analysis with likelihood-ratio backward elimination. The $P$ values used as entry and removal criteria in the backward elimination were 0.05 and 0.10 , respectively. Single colinearity was evaluated with the Pearson's correlation with the independent variable, and multicolinearity was evaluated with the variance inflation factor (VIF). To explore the impact of organ dysfunction severity on in-hospital mortality, three models were developed: 1) a model using admission SOFA; 2) a model using maximum SOFA, and 3) a model using TMS (to explore the impact of the worst function of each organ on in-hospital mortality irrespective of the time of occurrence). Significance was considered as $P$ $<0.05$ (two-tailed). All statistical tests were performed using the commercial package SPSS 13.0 for Windows (USA).

\section{Results}

The general features of all 116 patients (59 SLE and the 57 other-SRD patients) enrolled in the study are shown in Table 1. Data regarding only SLE patients such as autoantibodies, immunosuppression and time from SLE diagnosis to ICU admission are shown in Table 2. Table 3 indicates whether life support was used on
Table 1. Characteristics of all patients at admission.

\begin{tabular}{|c|c|c|c|}
\hline & $\begin{array}{l}\text { Whole group } \\
\qquad(N=116)\end{array}$ & $\begin{array}{l}\text { Other-SRDs } \\
(\mathrm{N}=57)\end{array}$ & $\begin{array}{c}\text { SLE } \\
(N=59)\end{array}$ \\
\hline \multicolumn{4}{|l|}{ Characteristics } \\
\hline Age, years (mean \pm SD) & $41 \pm 17$ & $50 \pm 16$ & $32 \pm 12^{*}$ \\
\hline Female/male gender, $\mathrm{N}(\%)$ & $97(84) / 19(16)$ & $16(72) / 41(28)$ & $56(95) / 3(5)^{\star *}$ \\
\hline Race (black/white), N (\%) & $19(25) / 87(75)$ & $10(18) / 47(82)$ & $19(32) / 40(68)$ \\
\hline APACHE II score (mean \pm SD) & $18.62 \pm 7.98$ & $18.81 \pm 7.38$ & $18.43 \pm 8.58$ \\
\hline Medical/surgical patients, N (\%) & $101(87) / 15(13)$ & $48(84) / 9(16)$ & $53(90) / 6(10)$ \\
\hline \multicolumn{4}{|l|}{ Origin of patients, $\mathrm{N}(\%)$} \\
\hline Ward & $70(60)$ & $36(64)$ & $34(58)$ \\
\hline Emergency room & $37(32)$ & $17(30)$ & $20(34)$ \\
\hline Other ICU & $5(4)$ & $2(4)$ & $3(5)$ \\
\hline Operating room & $4(3)$ & $2(4)$ & $2(3)$ \\
\hline \multicolumn{4}{|l|}{ Rheumatologic diagnosis, N (\%) } \\
\hline SLE & $59(51)$ & - & $59(100)$ \\
\hline Wegener's granulomatosis & $10(9)$ & $10(18)$ & - \\
\hline Dermatomyositis/polymyositis & $10(9)$ & $10(18)$ & - \\
\hline Rheumatoid arthritis & $7(6)$ & $7(12)$ & - \\
\hline $\begin{array}{l}\text { Mixed connective tissue } \\
\text { disease }\end{array}$ & $7(6)$ & $7(12)$ & - \\
\hline Spondyloarthritis & $5(4)$ & $5(9)$ & - \\
\hline Systemic sclerosis & $3(3)$ & $3(5)$ & - \\
\hline Sjögren syndrome & $3(3)$ & $3(5)$ & - \\
\hline Antiphospholipid syndrome & $3(3)$ & $3(5)$ & - \\
\hline Pulmonary-renal syndrome & $3(3)$ & $3(5)$ & - \\
\hline Takayasu's arteritis & $2(2)$ & $2(4)$ & - \\
\hline Behçet's disease & $2(2)$ & $2(4)$ & - \\
\hline Churg-Strauss syndrome & $1(1)$ & $1(2)$ & - \\
\hline Adult-onset Still's disease & $1(1)$ & $1(2)$ & - \\
\hline \multicolumn{4}{|l|}{ Co-morbid conditions, $\mathrm{N}(\%)$} \\
\hline Systemic arterial hypertension & $54(47)$ & $29(51)$ & $25(42)$ \\
\hline Diabetes mellitus & $7(6)$ & $3(5)$ & $4(7)$ \\
\hline Chronic renal failure & $29(25)$ & $9(16)$ & $20(34)^{\star *}$ \\
\hline Chronic heart failure & $17(15)$ & $7(12)$ & $10(17)$ \\
\hline $\begin{array}{l}\text { Chronic obstructive } \\
\text { pulmonary disease }\end{array}$ & $5(4)$ & $5(9)$ & $0(0)^{* *}$ \\
\hline Previous thrombotic event & $26(22)$ & $13(23)$ & $13(22)$ \\
\hline \multicolumn{4}{|l|}{ Syndrome at admission, $\mathrm{N}(\%)$} \\
\hline Respiratory failure & $53(46)$ & $35(61)$ & $18(31)^{* *}$ \\
\hline Shock & $31(27)$ & $8(14)$ & $23(39)^{\star *}$ \\
\hline CNS disturbances & $15(13)$ & $4(7)$ & $11(19)$ \\
\hline Renal failure & $10(9)$ & $5(9)$ & $5(9)$ \\
\hline Postoperative status & $7(6)$ & $5(9)$ & $2(3)$ \\
\hline \multicolumn{4}{|c|}{ Etiology of admission syndrome, $\mathrm{N}(\%)$} \\
\hline Infection & $42(36)$ & $23(40)$ & $19(32)$ \\
\hline Flare & $36(31)$ & $19(33)$ & $17(29)$ \\
\hline Infection + flare & $25(22)$ & $8(14)$ & $17(29)$ \\
\hline Other & $13(11)$ & $7(12)$ & $6(10)$ \\
\hline
\end{tabular}

Other-SRDs = other systemic rheumatic diseases; SLE = systemic lupus erythematosus; $\mathrm{APACHE}=$ acute physiological and chronic health evaluation score; CNS = central nervous system. ${ }^{*} \mathrm{P}<0.05$ compared to other-SRDs (unpaired $t$-test). ${ }^{* *} \mathrm{P}<0.05$ compared to other-SRDs (Fisher exact test or chi-square statistics, as appropriate). 
Table 2. Characteristics of patients with systemic lupus erythematosus.

\begin{tabular}{|c|c|c|}
\hline & \multicolumn{2}{|c|}{$\mathrm{N}(\%)$} \\
\hline \multicolumn{3}{|l|}{ Autoantibodies ${ }^{a}$} \\
\hline Antinuclear antibodies & \multicolumn{2}{|c|}{$55(100)$} \\
\hline Anti-double-stranded DNA (anti-dsDNA) & \multicolumn{2}{|c|}{$30(55)$} \\
\hline Anti-RNP & \multicolumn{2}{|c|}{$23(42)$} \\
\hline Anti-Sm & \multicolumn{2}{|c|}{$14(25)$} \\
\hline Anti-ribosomal P & \multicolumn{2}{|c|}{$13(24)$} \\
\hline Anti-Ro/SS-A & \multicolumn{2}{|c|}{$21(38)$} \\
\hline Anti-La/SS-B & \multicolumn{2}{|c|}{$2(4)$} \\
\hline Anti-cardiolipin & \multicolumn{2}{|c|}{$6(11)$} \\
\hline \multirow[t]{2}{*}{ Time from SLE diagnosis to ICU admission - days, median [IQR] } & \multicolumn{2}{|c|}{$1308[30-3763]$} \\
\hline & Pre-ICU admission & During ICU stay ${ }^{b}$ \\
\hline \multicolumn{3}{|l|}{ Immunosuppressive drugs } \\
\hline Chloroquine & $23(39)$ & $1(2)$ \\
\hline Corticosteroids & $51(86)$ & $53(96)$ \\
\hline Mycophenolate mophetil & $7(12)$ & $1(2)$ \\
\hline Tacrolimus & $1(2)$ & $0(0)$ \\
\hline Methotrexate & $4(7)$ & $0(0)$ \\
\hline Cyclophosphamide & $10(17)$ & $7(13)$ \\
\hline Azatioprine & $14(24)$ & $0(0)$ \\
\hline Plasmapheresis & $0(0)$ & $4(7)$ \\
\hline Gammaglobulin & $0(0)$ & $6(11)$ \\
\hline
\end{tabular}

aData not available for 4 patients. ${ }^{b}$ Data not available for 5 patients. IQR $=$ interquartile range.

the patients during the ICU stay as well as other diagnoses and outcomes. Eleven patients had adverse reactions to treatment drugs: severe acute pancreatitis in 4 patients, cumarinic poisoning in 3 patients, toxic epidermal necrolysis in 2 patients, myelosuppression in 1 patient, and acute pulmonary edema secondary to intravenous human immunoglobulin in 1 patient.

The 60-day probability of survival is shown in Figure 1. Panel A shows the probability of crude survival of SLE vs other-SRD patients, and Panel B shows the probability of survival of SLE vs other-SRD patients adjusted for age, gender, chronic renal failure, chronic obstructive pulmonary disease, admission syndrome, and any hemorrhage evidence. The characterization of organ dysfunctions observed at admission and during the ICU stay, using the SOFA score, is shown in Table 4.

The univariate and multivariate analyses of data associated with the in-hospital mortality of the whole group of critically ill rheumatologic patients are shown in Table 5. To explore the impact of the occurrence of non-synchronic organ dysfunction on in-hospital mortality, we constructed a third model using TMS instead of the maximum SOFA as an independent variable to measure organ dysfunction. In this new multivariate model, age [odds ratio $(\mathrm{OR})=$
1.05, 95\% confidence interval $(\mathrm{Cl})=1.02-1.09, \mathrm{P}=0.004$, $\mathrm{VIF}=1.060)$, total maximum SOFA $(\mathrm{OR}=1.32,95 \% \mathrm{Cl}$ $=1.19-1.47, \mathrm{P}<0.001, \mathrm{VIF}=1.056)$ and admission from the emergency unit $(\mathrm{OR}=0.19,95 \% \mathrm{Cl} 0.05-0.64, \mathrm{P}=$ 0.007 , VIF $=1.011$ ) were independently associated with in-hospital mortality.

\section{Discussion}

Few studies have analyzed the clinical features, prognosis and outcome of critically ill SRD patients in the ICU $(2,4-6)$. In the present study, we report one of the largest samples in the current literature analyzing these patients. Moreover, to our knowledge, this is the first study comparing SLE and other-SRD patients and also analyzing the SOFA score for the diagnosis and quantification of organ dysfunction in this setting.

The ICU and in-hospital mortality rates were similar to the most recent reports $(5,11)$ and lower than in previous studies $(4,6,31)$ (Table 3$)$. This fact may reflect advances in ICU management and rheumatologic care. Godeau et al. $(4,6)$ have shown that the mortality of critically ill SLE patients is lower than that of other-SRD patients. In contrast, Ansell et al. (31) have suggested that SLE patients have 
a particularly poor survival rate. However, these studies were not designed to evaluate this issue. The present study demonstrated that the survival of the SLE group did not differ from that of the other-SRD patient group, which does not support the pre-study hypothesis (Figure 1). The crude survival was higher in the SLE group despite several features classically associated with worse outcomes, such as major incidence of chronic renal failure (32), higher LOS in the hospital and higher incidence of shock at admission to the ICU (33). However, SLE patients were predominantly young women, a factor strongly associated with better outcome $(29,34)$. Ultimately, the balance of these characteristics resulted in a similar survival rate.

The association of alveolar hemorrhage, pneumonia,

Table 3. Patient support in the ICU, secondary diagnosis and outcomes.

\begin{tabular}{|c|c|c|c|}
\hline & Whole group $(\mathrm{N}=116)$ & Other-SRDs $(\mathrm{N}=57)$ & SLE $(N=59)$ \\
\hline \multicolumn{4}{|l|}{ Support during ICU stay } \\
\hline Non-invasive positive ventilation, $\mathrm{N}(\%)$ & $46(40)$ & $23(40)$ & $23(39)$ \\
\hline Mechanical ventilation, $\mathrm{N}(\%)$ & $60(52)$ & $32(56)$ & $28(48)$ \\
\hline Length of mechanical ventilation, median [IQR] & $2.5[1-5]$ & $3.5[1.3-6.8]$ & $2[1-4]$ \\
\hline Renal replacement therapy, N (\%) & $26(22)$ & $10(18)$ & $16(27)$ \\
\hline Use of antibiotics, $\mathrm{N}(\%)$ & $81(70)$ & $37(65)$ & $44(75)$ \\
\hline Vasoactive drugs, $\mathrm{N}(\%)$ & $46(40)$ & $26(46)$ & $20(34)$ \\
\hline Septic syndrome, N (\%) & $67(58)$ & $31(54)$ & $36(61)$ \\
\hline Sepsis & $14(21)$ & $5(16)$ & $9(25)$ \\
\hline Severe sepsis & $31(46)$ & $13(42)$ & $18(50)$ \\
\hline Septic shock & $22(33)$ & $13(42)$ & $9(25)$ \\
\hline \multicolumn{4}{|l|}{ Infection source, N (\%) } \\
\hline Lung & $32(48)$ & $21(68)$ & $11(31)^{*}$ \\
\hline Urinary tract & $10(15)$ & $4(13)$ & $6(17)$ \\
\hline Skin/soft tissues & $8(12)$ & $4(13)$ & $4(11)$ \\
\hline Abdominal & $8(12)$ & $1(3)$ & $7(19)$ \\
\hline Blood infection & $6(9)$ & $1(3)$ & $5(17)$ \\
\hline CNS & $2(3)$ & $0(0)$ & $2(6)$ \\
\hline Articular & $1(2)$ & $0(0)$ & $1(3)$ \\
\hline Evidence of hemorrhage, $\mathrm{N}(\%)$ & $33(28)$ & $20(35)$ & $13(22)$ \\
\hline Alveolar & $21(64)$ & $15(75)$ & $6(46)^{*}$ \\
\hline Abdominal & $6(18)$ & $2(10)$ & $4(31)$ \\
\hline CNS & $6(18)$ & $3(15)$ & $3(23)$ \\
\hline Evidence of activity of rheumatic disease, $\mathrm{N}(\%)$ & $61(53)$ & $27(47)$ & $34(58)$ \\
\hline New-onset rheumatic disease in the ICU, N (\%) & $6(5)$ & $2(4)$ & $4(7)$ \\
\hline Adverse reaction to drugs/treatment, $\mathrm{N}(\%)$ & $11(9)$ & $2(4)$ & $9(15)$ \\
\hline \multicolumn{4}{|l|}{ Outcomes } \\
\hline LOS in ICU, median [IQR] & $6[3-8]$ & $5[2-7]$ & $6[3-11]$ \\
\hline LOS in hospital, median [IQR] & $15[11-30]$ & 12 [8-19] & $22[14-35]^{* *}$ \\
\hline ICU mortality, N (\%) & $31(27)$ & $19(33)$ & $12(20)$ \\
\hline In-hospital mortality, N (\%) & $42(36)$ & $24(42)$ & $18(31)$ \\
\hline \multicolumn{4}{|l|}{ Unit after ICU discharge, N (\%) } \\
\hline Ward & $61(72)$ & $27(71)$ & $34(72)$ \\
\hline Step-down unit & $23(27)$ & $11(29)$ & $12(26)$ \\
\hline Other ICU & $1(1)$ & $0(0)$ & $1(2)$ \\
\hline ICU re-admission, N (\%) & $18(21)$ & $7(18)$ & $11(23)$ \\
\hline One & $11(61)$ & $4(11)$ & $7(15)$ \\
\hline Two or more & $7(39)$ & $3(8)$ & $4(9)$ \\
\hline
\end{tabular}

Other-SRDs = other systemic rheumatic diseases; SLE = systemic lupus erythematosus; $C N S=$ central nervous system; LOS = length-of-stay; IQR = interquartile range. ${ }^{*} P<0.05$ compared to other-SRDs (Fisher exact test or chi-square statistics as appropriate). ${ }^{* *} \mathrm{P}<0.05$ compared to other-SRDs (Mann-Whitney test). 
A

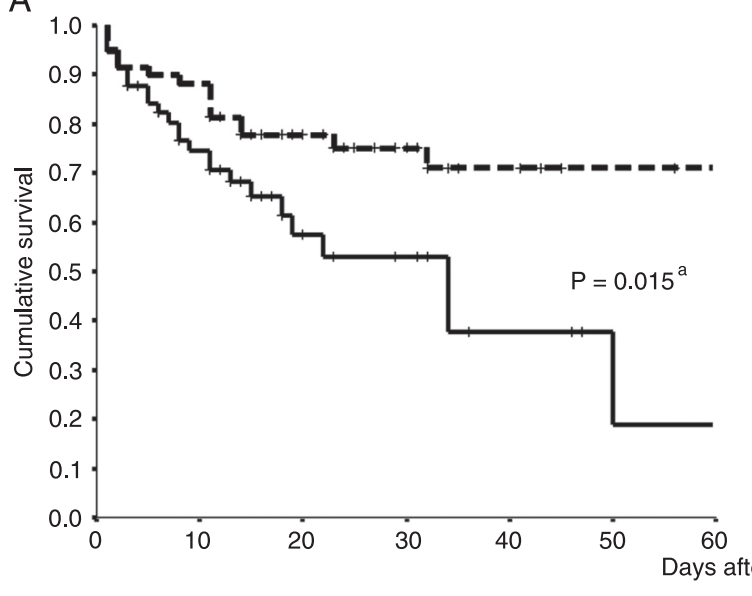

B

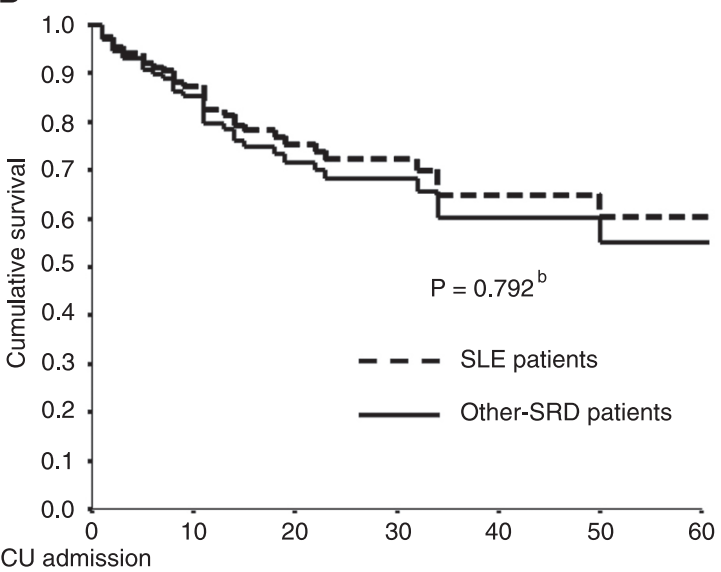

Number at risk

SLE patients $\begin{array}{lllllll}59 & 52 & 46 & 45 & 44 & 44 & 41\end{array}$ Other-SRD patients 57 $43 \quad 37$

$\begin{array}{llll}36 & 34 & 33 & 33\end{array}$

$\begin{array}{lllllll}59 & 52 & 46 & 45 & 44 & 44 & 41 \\ 57 & 43 & 37 & 36 & 34 & 33 & 33\end{array}$

Figure 1. Actuarial 60-day survival among 116 rheumatologic patients with systemic lupus erythematosus (SLE) or other systemic rheumatologic diseases (SRD) after ICU admission. Panel $A$ shows the Kaplan-Meyer probability of crude survival curve, and Panel $B$ shows the 60-day probability of the survival curve adjusted for age, gender, chronic renal failure, chronic lung disease, admission syndrome, and hemorrhage evidence. ap value using the log-rank test. ${ }^{\mathrm{b}} \mathrm{P}$ value using the Cox proportional-hazards regression model with the non-balanced variables between groups as covariates.

chronic obstructive pulmonary disease, and SRD with pulmonary involvement in the other-SRD group could explain the higher respiratory SOFA at admission. In this group, the occurrence of severe respiratory dysfunction (respiratory SOFA >2) was also higher than in the SLE group (Table 4). However, during the ICU stay the incidence of severe respiratory dysfunction was similar between groups. Furthermore, the need for noninvasive and invasive MV was similar for all groups, which may indicate a higher ICU incidence of adverse events in the SLE group. It is interesting to note that our incidence of MV (52\%) was lower than reported for other case series $(68-87 \%)(10,31)$. A possible explanation for this fact was the use of NPPV ( $40 \%$ of patients), a factor classically associated with fewer intubations in patients with hypoxemic respiratory failure (35). SLE patients had more chronic renal failure before ICU admission, which could explain the higher renal SOFA score on admission and during the ICU stay. Renal failure is common in SLE and strongly related to clinical outcome $(3,31)$. However, in our patients, when taking into account only severe renal failure (renal SOFA >2) on ICU admission and during the ICU stay, the occurrence was similar for all groups, as was the need for RRT. The development of acute renal failure associated with critical illness in other-SRD patients could explain the similar severe renal dysfunction and the need for RRT in both groups. Moreover, the frequency of thrombocytopenia has been reported to be as high as $40 \%$, and is strongly associated with mortality in SLE (36). In this setting, the marked occurrence of hematological dysfunc- tion in the SLE group during the ICU stay may represent not only disease activity but also dysfunction secondary to other critically ill injuries (37).

Analysis of the group as a whole (116 patients) showed that our patients are younger than those in other studies on SRDs in the literature $(4,6)$ (Table 1$)$. This may be related to the current recognition of milder forms of SRD and the prevalence in the cited studies $(4,6)$ of patients with diagnoses of rheumatoid arthritis and systemic vasculitis, diseases typically diagnosed in older patients (1). Respiratory failure was the main cause of ICU admission in our study, a finding similar to other samples of SRD (4) and SLE (10) patients. Regarding the etiology of ICU admission syndrome, infection and flare were common. Moreover, in $22 \%$ of our patients the etiologic diagnosis of ICU admission syndrome was related to infection plus flare, which highlights the difficulty in distinguishing between the two diagnoses (Table 1). The differential diagnosis between infection and flare is a challenge in general SRD patients, mainly because the therapeutic approaches are antagonistic. Thus, the treatment instituted often includes empirical antibiotic treatment plus systemic immunosuppression (38).

Regarding the prognostic factors (Table 5), the APACHE II score was not independently associated with in-hospital mortality, which agrees with previous studies showing that the APACHE II is not associated $(10,31)$ or weakly associated $(5,11)$ with mortality. Therefore, it seems that the APACHE II score is not a good tool for predicting mortality in SRD patients. This is probably related to the small number 
Table 4. Characterization of organ dysfunctions using the SOFA score at admission and during the ICU stay.

\begin{tabular}{|c|c|c|c|}
\hline & Whole group $(\mathrm{N}=116)$ & Other-SRDs $(\mathrm{N}=57)$ & SLE $(N=59)$ \\
\hline Admission SOFA, mean \pm SD & $5.5 \pm 4.7$ & $5.1 \pm 4.1$ & $5.9 \pm 5.1$ \\
\hline Neurological & $0.8 \pm 1.3$ & $0.6 \pm 1.1$ & $0.9 \pm 1.4$ \\
\hline Cardiovascular & $0.9 \pm 1.4$ & $0.9 \pm 1.4$ & $0.8 \pm 1.4$ \\
\hline Respiratory & $1.5 \pm 1.3$ & $1.8 \pm 1.4$ & $1.2 \pm 1.2^{*}$ \\
\hline Renal & $1.3 \pm 1.6$ & $0.9 \pm 1.4$ & $1.6 \pm 1.6^{*}$ \\
\hline Hepatic & $0.3 \pm 0.7$ & $0.2 \pm 0.6$ & $0.4 \pm 0.7$ \\
\hline Hematological & $0.8 \pm 1.3$ & $0.6 \pm 1.2$ & $1.0 \pm 1.3^{*}$ \\
\hline Maximum SOFA, mean \pm SD & $7.4 \pm 5.4$ & $6.9 \pm 5.3$ & $7.8 \pm 5.5$ \\
\hline Neurological & $1.4 \pm 1.6$ & $1.2 \pm 1.5$ & $1.5 \pm 1.7$ \\
\hline Cardiovascular & $1.5 \pm 1.7$ & $1.5 \pm 1.7$ & $1.4 \pm 1.6$ \\
\hline Respiratory & $2.0 \pm 1.3$ & $2.2 \pm 1.5$ & $1.8 \pm 1.3$ \\
\hline Renal & $1.7 \pm 1.7$ & $1.4 \pm 1.6$ & $2.0 \pm 1.7^{*}$ \\
\hline Hepatic & $0.4 \pm 0.7$ & $0.3 \pm 0.6$ & $0.5 \pm 0.8$ \\
\hline Hematological & $1.1 \pm 1.4$ & $0.8 \pm 1.3$ & $1.4 \pm 1.5^{\star}$ \\
\hline Total maximum SOFA, mean \pm SD & $8.0 \pm 5.8$ & $7.5 \pm 5.6$ & $8.6 \pm 6.0$ \\
\hline Mean SOFA, mean \pm SD & $5.3 \pm 4.5$ & $5.0 \pm 4.3$ & $5.6 \pm 4.7$ \\
\hline Delta SOFA, mean \pm SD & $1.9 \pm 3.3$ & $1.8 \pm 3.6$ & $1.9 \pm 3.0$ \\
\hline Day of maximum SOFA, median [IQR] & $1[1-3]$ & $1[1-3]$ & $2[1-3]$ \\
\hline No. of dysfunctions at admission, median [IQR] & $1[0-2]$ & $1[0-2]$ & $1[0-2]$ \\
\hline \multicolumn{4}{|l|}{ Occurrence of dysfunction at admission, $\mathrm{N}(\%)$} \\
\hline Neurological & $19(16)$ & $7(12)$ & $12(20)$ \\
\hline Cardiovascular & $21(18)$ & $12(21)$ & $9(15)$ \\
\hline Respiratory & $32(28)$ & $22(39)$ & $10(17)^{* *}$ \\
\hline Renal & $28(24)$ & $10(18)$ & $18(31)$ \\
\hline Hepatic & $1(1)$ & $0(0)$ & $1(2)$ \\
\hline Hematological & $15(13)$ & $5(9)$ & $10(17)$ \\
\hline No. of dysfunctions during ICU stay, median [IQR] & $1[0-3]$ & $1[0-2]$ & $1[0.5-2.5]$ \\
\hline \multicolumn{4}{|l|}{ Occurrence of dysfunctions during ICU stay, N (\%) } \\
\hline Neurological & $34(29)$ & $14(25)$ & $20(34)$ \\
\hline Cardiovascular & $37(32)$ & $20(35)$ & $17(29)$ \\
\hline Respiratory & $50(43)$ & $27(47)$ & $23(39)$ \\
\hline Renal & $42(36)$ & $16(28)$ & $26(44)$ \\
\hline Renal (attributable to disease activity) & $19(16)$ & $4(7)$ & $15(25)^{* *}$ \\
\hline Hepatic & $1(1)$ & $0(0)$ & $1(2)$ \\
\hline Hematological & $25(22)$ & $8(14)$ & $17(29)^{* *}$ \\
\hline
\end{tabular}

SOFA = sequential organ failure assessment score; Other-SRDs = other systemic rheumatic diseases; SLE = systemic lupus erythematosus; IQR = interquartile range. Organ dysfunction means SOFA $>2$. ${ }^{*} \mathrm{P}<0.05$ compared to other-SRDs (unpaired $t$-test). ${ }^{* *} \mathrm{P} \leq 0.05$ compared to other-SRDs (Fisher exact test or chi-square statistics as appropriate).

of SRD patients used in the validation of the score (29) and to the fact that SRD patients are generally younger than the general population of critically ill patients. In our study age was independently and consistently associated with in-hospital mortality as well as admission from the emergency room. This result agrees with the current literature, in which young age and emergency room admission (when compared to admission from the ward) are protective factors in general critically ill patients (39). Bleeding was common in our patients, and it has been related to poor outcomes in critically ill patients with SLE (10). In contrast, we did not find it as an outcome factor in multivariate analysis, probably because the incidence of bleeding in the SLE group was lower than in the other-SRD patients. Moreover, alveolar hemorrhage, the most common site of bleeding in our sample, was directly associated with the need for $\mathrm{MV}$, which was one of the main factors associated with outcome. We found that the SOFAscore was a good predictor of in-hospital mortality in SRD patients, as it was in other specific critically ill patients (40). However, admission SOFA was not associ- 
Table 5. Univariate and multivariate analysis of variables associated with the in-hospital mortality of critically ill rheumatologic patients.

\begin{tabular}{|c|c|c|c|c|c|c|c|c|}
\hline \multirow[t]{2}{*}{ Variable } & \multicolumn{2}{|c|}{ Univariate analysis ${ }^{a}$} & \multicolumn{3}{|c|}{ Multivariate analysis ${ }^{\mathrm{b}}$} & \multicolumn{3}{|c|}{ Multivariate analysis ${ }^{\mathrm{C}}$} \\
\hline & OR $(95 \% \mathrm{Cl})$ & $\mathrm{P}$ & OR $(95 \% \mathrm{Cl})$ & $\mathrm{P}$ & VIF & OR $(95 \% \mathrm{Cl})$ & $\mathrm{P}$ & VIF \\
\hline Age & 1.05 (1.02-1.07) & 0.001 & $1.05(1.02-1.11)$ & 0.002 & 1.053 & 1.05 (1.02-1.09) & 0.005 & 1.060 \\
\hline APACHE II & $1.07(1.02-1.13)$ & 0.008 & - & - & - & - & - & - \\
\hline Admission SOFA & $1.20(1.09-1.31)$ & $<0.001$ & - & - & - & Not included & - & - \\
\hline Maximum SOFA & $1.38(1.23-1.55)$ & $<0.001$ & Not included & - & - & $1.39(1.22-1.59)$ & $<0.001$ & 1.011 \\
\hline No. of co-morbidities & $1.48(1.04-2.09)$ & 0.028 & - & - & - & - & - & - \\
\hline SLE & $0.60(0.28-1.30)$ & 0.195 & - & - & - & - & - & - \\
\hline Surgical patients & $0.40(0.11-1.50)$ & 0.173 & - & - & - & - & - & - \\
\hline $\begin{array}{l}\text { Emergency room } \\
\text { admission }\end{array}$ & $0.51(0.22-1.20)$ & 0.125 & $0.243(0.08-0.75)$ & 0.014 & 1.016 & $0.18(0.05-0.63)$ & 0.007 & 1.056 \\
\hline Infection & $1.31(0.60-2.83)$ & 0.496 & - & - & - & - & - & - \\
\hline Disease activity & $0.63(0.29-1.35)$ & 0.234 & - & - & - & - & - & - \\
\hline Bleeding & $2.47(1.08-5.64)$ & 0.033 & - & - & - & - & - & - \\
\hline Need for MV & $9.80(3.81-25.18)$ & $<0.001$ & $6.94(2.43-19.84)$ & $<0.001$ & 1.126 & - & - & - \\
\hline Need for RRT & $3.18(1.30-7.82)$ & 0.012 & - & - & - & - & - & - \\
\hline Vasopressor & $2.29(1.05-4.98)$ & 0.036 & - & - & - & - & - & - \\
\hline
\end{tabular}

aOnly variables with a $\mathrm{P}$ value $<0.2$ in the univariate analysis were used in the multivariate analysis; bultivariate analysis including admission SOFA and not including maximum SOFA; CMultivariate analysis including maximum SOFA and not including admission SOFA; OR = odds ratio; $\mathrm{Cl}=$ confidence interval; VIF = variance inflation factor; APACHE = acute physiological and chronic health evaluation score; SOFA = sequential organ failure assessment score; SLE = systemic lupus erythematosus; MV = mechanical ventilation; RRT = renal replacement therapy.

ated with in-hospital mortality in the multivariate analysis, probably because severe respiratory dysfunction requiring MV was a stronger mortality predictor in the same analysis. Therefore, a worsening of other organ functions during ICU stay (maximum SOFA) was independently associated with in-hospital mortality, suggesting that the process leading to death is preceded by more severe MODS (7).

This study has several limitations. First, our sample was retrieved from a single tertiary hospital and, thus, our findings may not be applicable to other settings. Second, it is a retrospective analysis, and therefore we did not have access to some variables, such as the assessment of SRD activity using specific scores. Third, we did not evaluate longterm quality of life in our patients, an important outcome in view of the fact that SRD and critical illness are chronically debilitating processes.

In this large cohort of critically ill rheumatologic indi-

\section{References}

1. Cooper GS, Stroehla BC. The epidemiology of autoimmune diseases. Autoimmun Rev 2003; 2: 119-125.

2. Camargo JF, Tobon GJ, Fonseca N, Diaz JL, Uribe M, Molina $\mathrm{F}$, et al. Autoimmune rheumatic diseases in the intensive care unit: experience from a tertiary referral hospital and review of the literature. Lupus 2005; 14: 315-320.

3. Janssen NM, Karnad DR, Guntupalli KK. Rheumatologic viduals, SLE and other-SRD patients had similar 60-day survival. SLE patients were younger, had more renal and hematological failure, less respiratory failure and an increased incidence of shock at admission. The major dysfunctions in the total sample at admission and during ICU stay were respiratory and renal. Older patients and those with a need for MV and an increased number of failed organs were more susceptible to poor outcomes. In our sample, APACHE II was not an adequate mortality predictor. However, further prospective studies with these patients should be performed.

\section{Acknowledgments}

The authors are indebted to Dr. Leandro Utino Taniguchi for the statistical support. diseases in the intensive care unit: epidemiology, clinical approach, management, and outcome. Crit Care Clin 2002; 18: 729-748.

4. Godeau B, Boudjadja A, Dhainaut JF, Schlemmer B, Chastang $C$, Brunet $F$, et al. Outcome of patients with systemic rheumatic disease admitted to medical intensive care units. Ann Rheum Dis 1992; 51: 627-631. 
5. Moreels M, Melot C, Leeman M. Prognosis of patients with systemic rheumatic diseases admitted to the intensive care unit. Intensive Care Med 2005; 31: 591-593.

6. Godeau B, Mortier E, Roy PM, Chevret S, Bouachour G, Schlemmer B, et al. Short and longterm outcomes for patients with systemic rheumatic diseases admitted to intensive care units: a prognostic study of 181 patients. $J$ Rheumatol 1997; 24: 1317-1323.

7. Singer M, De Santis V, Vitale D, Jeffcoate W. Multiorgan failure is an adaptive, endocrine-mediated, metabolic response to overwhelming systemic inflammation. Lancet 2004; 364 : 545-548.

8. Ferreira FL, Bota DP, Bross A, Melot C, Vincent JL. Serial evaluation of the SOFA score to predict outcome in critically ill patients. JAMA 2001; 286: 1754-1758.

9. Moreno R, Vincent JL, Matos R, Mendonca A, Cantraine $F$, Thijs $L$, et al. The use of maximum SOFA score to quantify organ dysfunction/failure in intensive care. Results of a prospective, multicentre study. Working Group on Sepsis related Problems of the ESICM. Intensive Care Med 1999; 25: 686-696.

10. Hsu CL, Chen KY, Yeh PS, Hsu YL, Chang HT, Shau WY, et al. Outcome and prognostic factors in critically ill patients with systemic lupus erythematosus: a retrospective study. Crit Care 2005; 9: R177-R183.

11. Namendys-Silva SA, Baltazar-Torres JA, Rivero-Sigarroa E, Fonseca-Lazcano JA, Montiel-Lopez L, Dominguez-Cherit G. Prognostic factors in patients with systemic lupus erythematosus admitted to the intensive care unit. Lupus 2009; 18: $1252-1258$.

12. Tan EM, Cohen AS, Fries JF, Masi AT, McShane DJ, Rothfield NF, et al. The 1982 revised criteria for the classification of systemic lupus erythematosus. Arthritis Rheum 1982; 25: 1271-1277.

13. Bohan A, Peter JB. Polymyositis and dermatomyositis (second of two parts). N Engl J Med 1975; 292: 403-407.

14. Leavitt RY, Fauci AS, Bloch DA, Michel BA, Hunder GG, Arend WP, et al. The American College of Rheumatology 1990 criteria for the classification of Wegener's granulomatosis. Arthritis Rheum 1990; 33: 1101-1107.

15. Arnett FC, Edworthy SM, Bloch DA, McShane DJ, Fries JF, Cooper NS, et al. The American Rheumatism Association 1987 revised criteria for the classification of rheumatoid arthritis. Arthritis Rheum 1988; 31: 315-324.

16. Kasukawa R. Mixed connective tissue disease. Intern Med 1999; 38: 386-393.

17. Dougados $M$, van der Linden $S$, Juhlin $R$, Huitfeldt $B$, Amor B, Calin A, et al. The European Spondylarthropathy Study Group preliminary criteria for the classification of spondylarthropathy. Arthritis Rheum 1991; 34: 1218-1227.

18. Preliminary criteria for the classification of systemic sclerosis (scleroderma). Subcommittee for scleroderma criteria of the American Rheumatism Association Diagnostic and Therapeutic Criteria Committee. Arthritis Rheum 1980; 23: 581-590.

19. Vitali C, Bombardieri S, Moutsopoulos HM, Balestrieri G, Bencivelli W, Bernstein RM, et al. Preliminary criteria for the classification of Sjogren's syndrome. Results of a prospective concerted action supported by the European Community. Arthritis Rheum 1993; 36: 340-347.

20. Wilson WA, Gharavi AE, Koike T, Lockshin MD, Branch DW, Piette JC, et al. International consensus statement on preliminary classification criteria for definite antiphospholipid syndrome: report of an international workshop. Arthritis Rheum 1999; 42: 1309-1311.

21. Papiris SA, Manali ED, Kalomenidis I, Kapotsis GE, Karakatsani A, Roussos C. Bench-to-bedside review: pulmonaryrenal syndromes - an update for the intensivist. Crit Care 2007; 11: 213.

22. Arend WP, Michel BA, Bloch DA, Hunder GG, Calabrese LH, Edworthy SM, et al. The American College of Rheumatology 1990 criteria for the classification of Takayasu arteritis. Arthritis Rheum 1990; 33: 1129-1134.

23. Criteria for diagnosis of Behcet's disease. International Study Group for Behcet's Disease. Lancet 1990; 335: 10781080.

24. Masi AT, Hunder GG, Lie JT, Michel BA, Bloch DA, Arend WP, et al. The American College of Rheumatology 1990 criteria for the classification of Churg-Strauss syndrome (allergic granulomatosis and angiitis). Arthritis Rheum 1990; 33: 1094-1100.

25. Yamaguchi M, Ohta A, Tsunematsu T, Kasukawa R, Mizushima Y, Kashiwagi $\mathrm{H}$, et al. Preliminary criteria for classification of adult Still's disease. J Rheumatol 1992; 19: 424-430.

26. Bone RC, Balk RA, Cerra FB, Dellinger RP, Fein AM, Knaus $W A$, et al. Definitions for sepsis and organ failure and guidelines for the use of innovative therapies in sepsis. The ACCP/ SCCM Consensus Conference Committee. American College of Chest Physicians/Society of Critical Care Medicine. Chest 1992; 101: 1644-1655.

27. Specks U. Diffuse alveolar hemorrhage syndromes. Curr Opin Rheumatol 2001; 13: 12-17.

28. Mehta RL, Kellum JA, Shah SV, Molitoris BA, Ronco C, Warnock DG, et al. Acute Kidney Injury Network: report of an initiative to improve outcomes in acute kidney injury. Crit Care 2007; 11: R31.

29. Knaus WA, Draper EA, Wagner DP, Zimmerman JE. APACHE II: a severity of disease classification system. Crit Care Med 1985; 13: 818-829.

30. Vincent JL, de Mendonca A, Cantraine F, Moreno R, Takala $J$, Suter PM, et al. Use of the SOFA score to assess the incidence of organ dysfunction/failure in intensive care units: results of a multicenter, prospective study. Working roup on "Sepsis-Related Problems" of the European Society of Intensive Care Medicine. Crit Care Med 1998; 26: 1793-1800.

31. Ansell SM, Bedhesi S, Ruff B, Mahomed AG, Richards G, Mer M, et al. Study of critically ill patients with systemic lupus erythematosus. Crit Care Med 1996; 24: 981-984.

32. Juneja D, Prabhu MV, Gopal PB, Mohan S, Sridhar G, Nayak $\mathrm{KS}$. Outcome of patients with end stage renal disease admitted to an intensive care unit in India. Ren Fail 2010; 32: 69-73.

33. Silva E, Pedro MA, Sogayar AC, Mohovic T, Silva CL, Janiszewski M, et al. Brazilian Sepsis Epidemiological Study (BASES study). Crit Care 2004; 8: R251-R260.

34. Prete PE, Majlessi A, Gilman S, Hamideh F. Systemic lupus erythematosus in men: a retrospective analysis in a Veterans Administration Healthcare System population. J Clin Rheumatol 2001; 7: 142-150.

35. Antonelli M, Conti G, Rocco M, Bufi M, De Blasi RA, Vivino $\mathrm{G}$, et al. A comparison of noninvasive positive-pressure ventilation and conventional mechanical ventilation in patients with acute respiratory failure. N Engl J Med 1998; 339: 429435. 
36. Fernandez M, Alarcon GS, Apte M, Andrade RM, Vila LM, Reveille JD. Systemic lupus erythematosus in a multiethnic US cohort: XLIII. The significance of thrombocytopenia as a prognostic factor. Arthritis Rheum 2007; 56: 614-621.

37. Moreau D, Timsit JF, Vesin A, Garrouste-Org, de Lassence A, Zahar JR, et al. Platelet count decline: an early prognostic marker in critically ill patients with prolonged ICU stays. Chest 2007; 131: 1735-1741.

38. Feng PH, Lin SM, Yu CT, Yu KH, Huang CD, Tsai YH, et al. Inadequate antimicrobial treatment for nosocomial infection is a mortality risk factor for systemic lupus erythematous patients admitted to intensive care unit. Am J Med Sci 2010;
340: $64-68$

39. Moreno RP, Metnitz PG, Almeida E, Jordan B, Bauer P, Campos RA, et al. SAPS 3 - From evaluation of the patient to evaluation of the intensive care unit. Part 2: Development of a prognostic model for hospital mortality at ICU admission. Intensive Care Med 2005; 31: 1345-1355.

40. Lamia B, Hellot MF, Girault C, Tamion F, Dachraoui F, Lenain $\mathrm{P}$, et al. Changes in severity and organ failure scores as prognostic factors in onco-hematological malignancy patients admitted to the ICU. Intensive Care Med 2006; 32: 1560-1568. 